\title{
Tobacco Roads: Histories of Technologies and a Transnational Economy
}

\author{
Melinda Plastas ${ }^{1,2}$, Maria Rentetzi ${ }^{1,2}$ \\ ${ }^{1}$ Department of Women and Gender Studies, Bates Colleges, Bates, IA, USA \\ ${ }^{2}$ Department of Humanities, Social Sciences and Law, National Technical University of Athens, Athens, Greece \\ Email:mplastas@bates.edu,mrentetz@vt.edu
}

Received 7 January 2016; accepted 11 April 2016; published 14 April 2016

Copyright ( 2016 by authors and Scientific Research Publishing Inc.

This work is licensed under the Creative Commons Attribution International License (CC BY).

http://creativecommons.org/licenses/by/4.0/

(c) (i) Open Access

\section{Keywords}

\author{
History of Tobacco, Tobacco Trade, Tobacco Technologies, Gender, Transnationalism, \\ History of Commodities
}

Impressed, we stare at the cover of a 1902 commercial catalogue published by the M.L. Herzog \& Co, the biggest tobacco monopoly in Europe at the time. Founded by Baron Pierre Herzog in 1889, the Austro-Hungarian monopoly was the Sultan's main supplier of tobacco. Advertising the trade connections to the Ottomans, the company's catalogue was used to boost tobacco sales worldwide and impressed with the extended network of its tobacco trade. The company's headquarters were in Budapest and their main site for processing tobacco was Cavalla, a town by the sea in northern Greece that was still under Ottoman rule. On the catalogue's cover also appeared several other Greek cities-Xanthi, Drama, Pravista, and Thessaloniki—all still part of the Ottoman Empire and locations where the company maintained tobacco warehouses and processing centers. In addition to Greece and the Ottoman Empire, the 1902 catalogue signaled the transnational reach of the tobacco and the Herzog Company as it referenced Haskovo in southern Bulgaria; Smyrna and Samsun in Asia Minor, and New York City where Herzog's 61 Broadway headquarters loomed as one of the biggest leaf tobacco importers in this North American city.

This collection of essays explores the aforementioned complex geographical, social, political, and economic networks that developed throughout the end of the nineteenth and through the twentieth century due to tobacco trade. By focusing on the circulation of tobacco as a commodity it seeks to elucidate the variety of dimensions that technological changes in tobacco production and processing carried for local cultures in Europe and beyond. While major historiographical studies look at tobacco through the production of cigars or cigarettes and their circulation in South and North America, the essays in this collection resituate our attention to European and Asian sites of processing tobacco leaves for export. By doing so it sheds light on several underexamined transnational routes of tobacco trade and to the history of local cultures strongly tied to the circuit of tobacco cultivation, har- 
vesting, and processing.

Commodities, like tobacco, offer an important framework for engaging the often-interlocking relationship of technology, production, science, labor, political economy, consumption, and culture. Likewise, they illuminate the interrelation of the local and the global. Howard Cox's The Global Cigarette: Origins and Evolution of British American Tobacco, 1880-1945 (Cox, 2000), for instance, demonstrated the transnational implications of tobacco commerce and colonialism as exemplified by BAT's expansion into China, India, South East Asia, and the Middle East. Other works, like Ian Gatley’s Tobacco: A Cultural History of How an Exotic Plant Seduced Civilization (Gatley, 2001) and Allan Kulikoff's Tobacco and Slaves: the Development of Southern Cultures in the Chesapeake 1680-1800 (Kulikoff, 1986) expanded the narrative into the transatlantic world. Carol Benedicts Golden-Silk: Smoke: A History of Tobacco in China, 1550-2010 (Benedicts, 2011) continued the long history format while securing the readers attention on one country and enhancing discussion of the relation of tobacco on Chinese culture, including gender norms. Two other monographs, Relli Schechter's, Smoking, Culture, and the Economy in the Middle East: The Egyptian Tobacco Market, 1850-2000 (Shechter, 2006) and Mary C. Neuburger's Balkan Smoke: Tobacco and the Making of Modern Bulgaria (Neuburger, 2012) continued the analysis of the influence of tobacco on culture documenting the production and negotiation of class, gender, and ethno-religious identities. Neuburger's work with its focus on the Macedonia region, the East-West political and cultural exchange between Vienna and Istanbul, and the accordant tensions over nationalism, signals the importance of the continued development of academic studies of tobacco's influence in the region.

As early as the 1980 s, historians of technology focused on the new industrial workplaces at the turn of the $20^{\text {th }}$ century as prosperous sites to explore ways of gendering technologies. Tobacco factories served as an ideal example. In "What This Country Needs Is a Good Five-Cent Cigar", (Cooper, 1998), Patricia A. Cooper took us to the cigar industry of the 1920s when the introduction of automatic cigar machinery forced the transformation of cigar making from handcraft to industrialized occupation and from a skilled craft for men to unskilled job for women. Studies on early methods of tobacco processing and packaging open up yet another fruitful area of research. On the crossroads of architecture and technology studies, Maria Rentetzi focused on Cavalla's tobacco warehouses as sites of multiple kinds of production — economic, discursive, and cultural—and as subversive of the boundaries between the factory and the city (Rentetzi, 2008). Inside the warehouses took place the actual processing and packaging of tobacco leaves, the production of unionists and ideological conflicts, the discursive formation of communist politics, the fabrication of new technologies as well as the construction of a gendered work culture. These spaces marked the city in an indelible way and dominated its urban planning both by their imposing presence and by the changes they initiated. As the class struggle moved from the factory to the urban space during the end of the nineteenth and early twentieth centuries, eventually, the factory and its life took over the city.

The articles curated by Maria Rentetzi and Melinda Plastas for this issue of Advances in Historical Studies (AHS) continue to excavate the role of tobacco in technology, culture, and politics—as witnessed in Cavalla —and encourage further local studies of this global commodity. This special edition of AHS grew out of an international workshop organized by Maria Rentetzi, one of the volume's editors, and hosted at a traditional tobacco warehouse in the city of Kavala (historically mentioned as Cavalla) in northern Greece in 2013. Melinda Plastas' earlier ethnographic and historical research on how tobacco haunts the economic, political, cultural, and personal structures and narratives of the city of Kavalla gave us an additional impulse to explore the history of this valuable commodity through diverse perspectives. The articles included here examine tobacco through distinct yet intersecting and converging roads: the circulation of artifacts and methods, the transfer of technological knowhow, the actors, the practices, and the industrial buildings. Authors' interests include tobacco trade and the development of new economic structures that accommodate the needs of tobacco merchants and monopolies while also influencing the work and daily life of tobacco processing communities. They question the mechanization of traditional tobacco processing methods and the shifting dynamics of work culture and politics that resulted from the introduction of new technologies. Using gender as an analytic tool, some of our authors focus on tobacco's influence on gendered norms in the worlds of work, politics, sexuality, family life, and culture. Their work builds upon an ever increasing scholarly attention to tobacco's influence on gender. Notably, the most comprehensive attention to the intersection of tobacco production and gender examines Macedonia, Greece and the Ottoman Empire. For instance, in addition to Neuburger's Balkan Smoke, historian Efi Avdela's (Avdela, 1998) scholarship elucidates the intersection of gender, labor, tobacco, and culture in Greece.

Other articles in this special edition investigate the geopolitics of tobacco and the influence of tobacco on 
cultural institutions and practices and ethnic politics. As many of the articles demonstrate, the end of the nineteenth century saw the organization of tobacco trade, the development of a new bank system based partially on tobacco economies, and the expansion of geopolitical negotiations closely related to the production and circulation of tobacco. Hence, the tobacco economy deeply influenced local tobacco leaf processing in southern Europe while transforming the communities that supported the development of cigarette industry in both central and south Europe. In addition to finance, the transfer of architectural styles and forms from northern European to tobacco centers in southern Europe, illustrates the transnational reach of tobacco capitalism in the form of urban development. Additionally, as many of the articles discuss, the shifting transnational tobacco economies gave shape to the ethno-religious relations of communities and workers. Despite differences in focus, each of our authors encourages new perspectives on the history of tobacco bringing front and center tobacco technologies, sites of tobacco processing, and ways of organizing the tobacco trade. The essays, covering the period from the late nineteenth century through the twentieth century, remind readers of the significance of tobacco trade to local, regional, and transnational geopolitics and culture. Likewise, and perhaps most importantly, the collection resituates our attention on the tobacco trade in Europe and Asia, especially Greece and the Ottoman Empire, illustrating its influence on the micro and macro development of economic, political, social, and cultural contours of diverse communities and peoples.

Our first author, Thanasis Betas, traces the transformation from the tobacco-shop to cigarette industry in early 20thcentury Greece focusing especially on Volos. The mechanization of the field through the introduction of cigarette-making machines and the increased use of female labor rendered the profession of the hand-made cigarette-maker obsolete. Using gender as an analytical tool, Betas explores issues in relation to labor history, such as wages, labor-specialization, and workplace hierarchies and authority. He argues that gender illuminates the shifts in power that emerged in and out of the workplace. Observing the process of the cigarette production before and after the mechanization in Greece, he draws our attention to a cigarette industry, which operated in Volos from 1918-1972 and scrutinizes the consequences that technological and organizational modifications have on labor.

Next, Christos Bakalis focuses yet on another unexplored area of tobacco cultivation in Greece. Between the years 1850-1970 the cultivation, processing and distribution of tobacco in the Aegean region gradually developed. Cultivation of tobacco started at the end of the 19th century, reached its peak in the first half of the 20th century and then declined due to either willful abandoned by the farmers or changes in state policies. These transformations affected the social and spatial structures of the region and at the same time contributed to the economic, social and cultural transformation of island communities. The rural life followed the rhythm of production, while the populations in urban centers lived at the pace of processing, manufacture, and marketing of the product. The impact of the rise and fall of the tobacco economy on rural and urban cultures was enormous and best understood through the symbolic spaces that emerged.

Dora Monioudi-Gavala acknowledges architecture of tobacco warehouses as closely intertwined with the social. Using Agrinio, Greece as her case study, the author demonstrates how tobacco warehouses transformed the town aesthetically and symbolically. The diverse architectural styles of the warehouses, hybrid confluences of art deco, classicist, and the Vienna school, illustrated the cosmopolitan and European lineage of the tobacco merchants involved in turning Agrinio, a western inland Greek city, into a key tobacco city. As Monioudi-Gavala shows, the construction of the tobacco warehouses in Agrinio during the interwar years marked a period of financial prosperity for the city and shifted its attention outward. Architectural technology, hence, influenced not only the technology of Agrinio's numerous tobacco warehouses, but also the very nature of the city itself.

In his study Dimitris Stergiopoulos questions if and how local financial and industrial growth was correlated to the structural changes of the Ottoman economy through the 19th century. He studies the program of radical reforms that the Ottoman Empire launched during this period intending to modernize the Empire and gradually integrate the Ottoman economy with European economies. The main reason for this integration was the need for cheap agricultural products and raw materials from the European economies and the disposal of their industrial products in the Ottoman market. Focusing especially on Kavala, Stergiopoulos explores the ways in which these reforms influenced the tobacco trade and tobacco related agricultural activity in the area hoping to understand the weight of the decisions of the central economic policy in the economic life of the regions.

Finally, focusing on Taiwan, Han-Hsiu Chen examines the way in which the transfer of technology of the tobacco curing method shaped the local social relationships in the country's tobacco settlement in the mid-twentieth century. Contextualizing Taiwan's tobacco history within the influence of twentieth century Japanese colonial policy, Chen illuminates how the Taiwanese adapted Japanese colonial policy and technology to create their own 
tobacco practices and cultures. As Chen examines, the curing of tobacco leaves, a demanding and complicated process, generated daily habits and cultural practices (song, shared meals, and the rhythms of social relations, for instance) that lasted until the mechanization of tobacco curing in the 1970s. Chen illustrates that with the demise of the original curing buildings and introduction of new technologies emerged a form of tobacco tourism, including cultural heritage projects, which rejuvenate interest in the social and technological aspects of tobacco curing. By drawing on documentary research and interviews conducted with farmers and residents in tobacco settlements in Taiwan, Chen explores the story of how people, place, and the tobacco industry are connected by this transfer of technology in the contemporary society.

Exploring the impact of tobacco production and related technologies on the economic, social, and political texture of communities assists in our understanding, more broadly, of the complex role of commodities in societies. Tobacco, like other global commodities (sugar and cotton, for instance), generated and continues to generate new forms of mechanization while concomitantly reaching into the social order of labor, culture, family, health, agriculture, and political economies. And, as Melinda Plastas' (Plastas, 2013) research on Kavala and other former tobacco communities in Europe and the United States underscores, industrial and agricultural tobacco continues to influence the culture, politics, memories and landscapes of communities long after its discontinuance. Through the phenomenon of tobacco museums, for instance, former tobacco communities negotiate and often reformulate the relationship of their tobacco past to the present state of their communities. And as "tobacco capitalism” (Benson, 2012) continues to influence the economic, cultural, and health landscapes of peoples around the world, deep historical case-studies, as offered in this special edition of AHS, remind us not only of the durability of tobacco's influence on people's and cultures, but also of the significance of local studies to the pursuit of understanding globalization's continuing effects.

\section{References}

Avdela, E. (1998). Class, Ethnicity and Gender in Post-Ottoman Thessaloniki. In B. Melman (Ed.), Borderlines: Genders and Identities in Peace and War (1880-1930) (pp. 421-438). London and New York: Routledge.

Benedicts, C. (2011). Golden-Silk Smoke: A History of Tobacco in China, 1550-2010. Berkeley, CA: University of California Press. http://dx.doi.org/10.1525/california/9780520262775.001.0001

Benson, P. (2012). Tobacco Capitalism: Growers, Migrant Workers, and the Changing Face of a Global Industry. Princeton, NJ: Princeton University Press.

Cooper, P. (1988). What This Country Needs Is a Good Five-Cent Cigar. Technology and Culture, 29, 779-807.

Kulikoff, A. (1986). Tobacco and Slaves: The Development of Southern Cultures in the Chesapeake, 1680-1800. Chapel Hill: University of North Carolina Press.

Neuburger, M. (2012). Balkan Smoke: Tobacco and the Making of Modern Bulgaria. Ithaca, NY: Cornell University Press.

Plastas, M. (2013). “To Know Tobacco”: Museums and Memory. Paper Presented at the Technology Transfer in the Tobacco Industry during the Early Twentieth Century conference, Kavalla, Greece.

Rentetzi, M. (2008). Configuring Identities Through Industrial Architecture and Urban Planning: Greek Tobacco Warehouses in Late Nineteenth and Early Twentieth Century. Science Studies, 21, 64-81.

Shechter, R. (2006). Smoking, Culture, and Economy in the Middle East: The Egyptian Tobacco Market, 1850-2000. London: I.B. Tauris and Company. 